\title{
Measurement equivalence of the English, Chinese and Malay versions of the World Health Organization quality of life (WHOQOL-BREF) questionnaires
}

Yin Bun Cheung ${ }^{1,2}$, Khung Keong Yeo ${ }^{3,4}$, Kok Joon Chong ${ }^{5}$, Eric Yin Hao Khoo ${ }^{5,6}$ and Hwee Lin Wee W, $^{*}$ (1)

\begin{abstract}
Background: The WHOQOL-BREF is a widely used questionnaire for measuring quality of life. It is important to establish the measurement equivalence of various language versions of WHOQOL-BREF so that scores from different language versions may be pooled together. The primary aim of this article was to evaluate the measurement equivalence of the English, Chinese and Malay versions of the WHOQOL-BREF.

Methods: We analysed data from the previously published, cross-sectional, WONDERS study and used linear regression models to adjust for potential confounding variables. Based on equivalence clinical trial methods, measurement equivalence was assessed by comparing 90\% confidence interval (Cl) of differences in scores across language versions with a predefined equivalence margin of 0.3 SD. Equivalence was achieved if the $90 \% \mathrm{Cl}$ fell within 0.3 SD. Data from 1203 participants, aged above 21 years, were analysed.

Results: Participants who completed the different language versions of WHOQOL-BREF expectedly differed in age, ethnicity, highest education level, marital status, smoking status and Body Mass Index (BMI). The English and Malay language versions were definitely equivalent for all domains. The English and Chinese language versions were definitely equivalent for physical and environmental domains but inconclusive for psychological and social domains. Likewise, for Chinese and Malay versions.

Conclusion: The English, Chinese and Malay language versions of the WHOQOL-BREF questionnaire may be considered equivalent, with evidence being more robust for some domains than the others. Given the large number of people who speak/ read Chinese and Malay, this study has widespread relevance.
\end{abstract}

Keywords: Quality of life, Equivalence, Patient-reported outcomes, Preference-based measures

\section{Background}

Patient reported outcomes (PRO) are reports obtained directly from patients about how they function or feel in relation to a health condition and its therapy, without interpretation of the patient's response by a clinician or anyone else [1]. PRO are used in clinical trials to evaluate the effectiveness of medical interventions from the patients' perspective [2], as a surrogate measure of the

\footnotetext{
* Correspondence: phawhl@nus.edu.sg

${ }^{7}$ Department of Pharmacy, Faculty of Science, National University of Singapore, Singapore, Singapore

${ }^{8}$ Saw Swee Hock School of Public Health, National University of Singapore,

Singapore, Singapore

Full list of author information is available at the end of the article
}

direct benefit to the patient's well-being [3]. The results of these studies inform healthcare decisions made by patients and their clinicians, influence the development of health policy and support licensing claims for medication [2].

World Health Organization Quality-of-Life Questionnaire (WHOQOL-BREF) is a health-related quality of life (HRQoL) assessment used as a PRO. The WHOQOL-BREF, an abbreviated version of WHOQOL-100, was developed as a cross-cultural questionnaire and is available in more than 20 languages [4]. It has since been used in many countries including United States of America [5, 6], Thailand [7, 8], India $[9,10]$, China $[11,12]$, Ghana $[13,14]$ and New

(c) The Author(s). 2019 Open Access This article is distributed under the terms of the Creative Commons Attribution 4.0 International License (http://creativecommons.org/licenses/by/4.0/), which permits unrestricted use, distribution, and reproduction in any medium, provided you give appropriate credit to the original author(s) and the source, provide a link to the Creative Commons license, and indicate if changes were made. The Creative Commons Public Domain Dedication waiver (http://creativecommons.org/publicdomain/zero/1.0/) applies to the data made available in this article, unless otherwise stated. 
Zealand $[15,16]$. In multinational clinical trials and trials within multi-ethnic societies, it is common to use multiple language versions of PRO questionnaires to cater to the different language needs of the study participants. Various language versions of the questionnaires are combined in order to increase the power and representativeness of the study. To do so, a pre-requisite is that the language versions are considered equivalent in terms of their measurement properties. [1] This is important as culture and language could affect the respondents' interpretation and responses to the HRQoL instruments. For example, in a study among students from Flanders, Belgium and Iran, [17] the authors reported that participants seem to respond differently to several items in the WHOQOL-BREF, especially those items in the physical and psychological domains. In another example, it was reported that the scores of one-third of the facets and domains in the WHOQOL-BREF were significantly different between the English and Hindi versions even though the questionnaires were completed by participants who are bilingual in English and Hindi. [18] Hence, the aim of this study is to evaluate the equivalence of the English, Chinese and Malay versions of the WHOQOL-BREF in Singapore.

Singapore is a multi-ethnic country, with Chinese, Malays and Indians making up the majority of the population. Although English is the main language of commerce and education, there is a sizeable proportion of the population who are more comfortable with their mother tongue languages $[19,20]$. The psychometric properties of the Tamil version of the WHOQOL-BREF have not been evaluated in Singapore. Hence, we did not use the Tamil version in our study. In addition, English, Chinese and Malay are also commonly spoken languages in other South East Asian countries such as Malaysia, the Philippines and Indonesia. [21] Furthermore, Standard Mandarin is spoken by a large number of people in China, Chinese Taipei, Malaysia and Indonesia. [22, 23]

\section{Methods}

\section{Participants and study design}

This study comprises of participants from the general population as well as two clinic samples. Ethics approval for this study was obtained from the National Healthcare Group Domain Specific Review Board (Ref. 2013/00747) as well as the SingHealth Centralised Institutional Review Board (Ref. 2015/2041). The clinic samples were chosen to enrich the dataset such that a wider spread of health status was represented, and the generalizability of the findings will be enhanced.

The general population participants were recruited by using a multi-stage cluster sampling using postcodes as the primary sampling unit (PSU) followed by the selection of household then the selection of respondents. Three call attempts (1st attempt and 2 call backs) were made at different days and different times of the week. Only one participant per household was selected. Participants in each contacted household were selected based on a pre-specified quota for language of interviews within each ethnicity interlocking with age and gender. The face-to-face interviews were conducted in the participants' home between October 2014 to January 2015.

The clinic participants were drawn from two separate studies in outpatient clinics in the National Heart Center Singapore (NHCS) and the Division of Endocrinology in the National University Hospital (NUH). Recruitment was conducted by research assistants via convenience sampling in the clinics while patients were waiting to see the doctor. In both clinical samples, patients must respond positively to either of these questions "Have you ever been told by a doctor previously that you have at least one of the following: blockage of the arteries to your heart, stroke, heart attack, peripheral arterial disease, or transient ischaemic attack, or kidney disease." and "Have you undergone at least one of the followings: heart bypass operation, stent insertion or brain surgery for stroke". Patients with recent acute myocardial infarction (STEMI), hemodynamic instability or gestational diabetes were excluded. Interviews were carried out between March 2015 and February 2016.

In both general population and clinic samples, to be eligible, the participant must be a Singapore Resident (including Singapore Citizens and Singapore Permanent Residents) aged 21 years and above who speaks English, Chinese (Mandarin) or Malay. Participants who speak only Tamil were excluded as the psychometric properties of the Tamil version of the WHOQOL-BREF have not been evaluated in Singapore. All participants read and signed the written informed consent form prior to commencement of the interviews. In Singapore, among the resident population aged 15 and over who are literate (95.9\%), 78.6\% speaks either English only (11.1\%) or English and at least one other language (67.5\%). English is the first language in school for all Singaporeans since 1959 [24].

\section{WHOQOL-BREF}

The WHOQOL-BREF was administered together with a socioeconomic and clinical questionnaire where information such as age, gender, ethnicity and self-reported medical conditions were captured. The WHOQOL-BREF is a 26-item questionnaire which includes one item from each of the 24 facets contained in the WHOQOL-100 and two additional items on overall quality of life and general health. The 24 items are organized into 4 domains, namely Physical Health, Psychological, Social Relationships and Environment. Three negatively phrased items were reversed scored. According to the user manual, domain scores were computed by taking the mean of the scores of 
the items that constitute the domain and multiplied by 4 so that the scores are directly comparable with those derived from WHOQOL-100. Mean substitution was performed for missing data by replacing the missing items with the mean of the non-missing item scores in the same domain if there was no more than one missing value per domain. The three language versions are official versions developed by the WHOQOL group.

\section{Statistical analyses}

Participants with more than $20 \%$ missing data were excluded from the analysis. Participants with missing data on participant characteristics were also excluded. Participants who completed the different language versions are expected to differ in demographic and socioeconomic characteristics, in particular, educational levels. Hence, we compared the participant characteristics using analysis of variance (ANOVA) for continuous variables such as age and chi-square test for categorical variables such as educational levels. We performed multiple linear regression analyses to compare the WHOQOL-BREF domain and total scores across the three language versions with the English version as the reference with adjustment for age, sex, education, marital status, smoking status, chronic disease and BMI. We entered the variables with a priori specification rather than stepwise regression. This strategy is more appropriate than other variable selection strategies when there is prior knowledge [25]. We did not adjust for ethnicity due to collinearity with language version. In addition, we did not adjust for multiple comparisons as Rothman has previously pointed out that doing so would reduce the type I error for null associations at the expense of increasing the type II error for those associations that are not null. $[26,27]$

In the multiple linear regression analyses, we compared the $90 \%$ confidence interval (CI) of the betas for the language variable and declared either the Chinese or the Malay version to be equivalent to English version if the $90 \% \mathrm{CI}$ falls completely within a pre-defined equivalence margin, to be non-equivalent if the $90 \% \mathrm{CI}$ falls completely outside the pre-defined equivalence margin or inconclusive if the $90 \% \mathrm{CI}$ overlaps with the equivalence margin $[28,29]$. This approach is similar to that of clinical trials that seek to demonstrate the equivalence of two treatments. The use of $p$-values to test for difference suffers the limitation of "no evidence of difference" does not provide "evidence of no difference". In contrast, the approach of using $\mathrm{CI}$ does provide evidence of no difference. Hence, the CI approach is preferred to the p-value approach. There are at least two schools of thoughts with regards to what magnitude of change score in HRQoL is considered a minimally important difference. Norman and colleague suggested that the minimally important difference (MID) is half a standard deviation (SD) [30] while Farivar et al. suggested that the MID is probably $0.3 \mathrm{SD}$ [31]. In our paper, we took the more conservative approach and defined the equivalence margin of difference in scores due to language version to be \pm 0.3 of a SD. In order to rule out unobserved cultural differences between ethnic groups, we did another set of multiple linear regression analyses, including only ethnic Chinese and ethnic Malay in the English vs Chinese and English vs Malay language version comparisons, respectively.

Based on a mean WHOQOL total score of approximately 75 and SD of 20 points observed in our dataset across the three language versions, we estimated that 175 participants are required in each group to detect a 6-point difference (i.e. $0.3 \mathrm{SD}$ ). This manuscript is a secondary analysis of the WONDERS study [32]. The main objective of the WONDERS study was to develop a mapping algorithm between WHOQOL-BREF and EQ-5D-5 L. [33] The WONDERS study recruited 428, 427 and 348 participants who completed the English, Chinese and Malay versions, respectively. Hence, we are adequately powered to perform the proposed analyses.

\section{Results}

\section{Participant characteristics}

There were 428, 427 and 348 participants who completed the English, Chinese and Malay versions of the study questionnaires, respectively. Table 1 shows the participant characteristics by the language version of the WHOQOL-BREF questionnaire. Participants who completed the English version have the lowest mean (SD) age compared to those who completed the Chinese (52.8 (15.6) years old) or Malay (50.7 (14.7) years old) versions. Those who completed the Chinese version were more likely to be older, married, non-smoker and had a lower average BMI. In addition, those who completed the Malay version tended to have lower education and have a higher average BMI. There was no significant difference in sex and presence of chronic disease across the language versions.

\section{Influence of language version on WHOQOL-BREF domain scores}

After adjusting for known determinants of the WHOQOL-BREF, confirmed equivalence of the English and Chinese WHOQOL-BREF language versions was demonstrated for two of the domains, namely physical and environmental while inconclusive equivalence was observed for two other domains (Table 2). The same observations were made when comparing the Chinese and Malay language versions. Confirmed equivalence between the English and Malay language versions was demonstrated for all four WHOQOL-BREF domains. 
Table 1 Participant characteristics by language version of WHOQOL-BREF questionnaire

\begin{tabular}{|c|c|c|c|c|c|}
\hline \multirow[t]{2}{*}{ Characteristics } & \multirow[t]{2}{*}{ Category } & \multicolumn{3}{|l|}{ Language } & \multirow[t]{2}{*}{$P$-value } \\
\hline & & English $(n=428)$ & Chinese $(n=427)$ & Malay $(n=348)$ & \\
\hline Age, mean (SD) & - & $48.0(16.5)$ & $52.8(15.6)$ & $50.7(14.7)$ & $<0.001$ \\
\hline Sex, $n(\%)$ & Female & 165 (38.6) & $184(43.1)$ & $151(43.4)$ & 0.288 \\
\hline \multirow[t]{3}{*}{ Ethnicity, n (\%) } & Chinese & $172(40.2)$ & $427(100.0)$ & $0(0.0)$ & $<0.001$ \\
\hline & Malay & $114(26.6)$ & $0(0.0)$ & $345(99.1)$ & \\
\hline & Indian & $142(33.2)$ & $0(0.0)$ & $3(0.9)$ & \\
\hline \multirow[t]{3}{*}{ Education, $n(\%)$} & Primary or below & $39(9.1)$ & $127(29.7)$ & $90(25.9)$ & N/A \\
\hline & Secondary & $219(51.2)$ & $178(41.7)$ & $222(63.8)$ & \\
\hline & Post-secondary & $170(39.7)$ & $122(28.6)$ & $36(10.3)$ & \\
\hline \multirow[t]{4}{*}{ Marital status, n (\%) } & Never married & $96(22.4)$ & $63(14.8)$ & $42(12.1)$ & 0.002 \\
\hline & Married & 302 (70.6) & 327 (76.6) & $265(76.2)$ & \\
\hline & Divorced/separated & $14(3.3)$ & $19(4.5)$ & $18(5.2)$ & \\
\hline & Widowed & $16(3.7)$ & $18(4.2)$ & $23(6.6)$ & \\
\hline \multirow[t]{3}{*}{ Smoking, n (\%) } & Non-smoker & $293(68.5)$ & $316(74.0)$ & $214(61.5)$ & 0.007 \\
\hline & Ex-smoker & $58(13.6)$ & $49(11.5)$ & $61(17.5)$ & \\
\hline & Current smoker & 77 (18.0) & $62(14.5)$ & $73(21.0)$ & \\
\hline Chronic disease, $n(\%)$ & Yes & $211(49.3)$ & $236(55.3)$ & $189(54.3)$ & 0.177 \\
\hline Body Mass Index $\left(\mathrm{kg} / \mathrm{m}^{2}\right)$, mean (SD) & - & $25.4(4.9)$ & $24.3(4.1)$ & $27.1(5.9)$ & $<0.001$ \\
\hline
\end{tabular}

${ }^{a}$ Difference in continuous variables tested by ANOVA; differences in categorical variables tested by Chi-square

For the second set of analyses to rule out unobserved cultural differences (Table 3), when comparing the English and Chinese language versions of WHOQOL-BREF, confirmed equivalence was demonstrated for all domains. When comparing the English and Malay language versions, confirmed equivalence was demonstrated for all domains except the environmental domain, where equivalence was inconclusive.

\section{Discussion}

In this study, we assessed the $90 \% \mathrm{CI}$ of the WHOQOL-BREF score differences between three language versions (English, Chinese and Malay) against a MID of 0.3 SD suggested by Farivar et al. [31]. The findings were slightly different depending on whether unobserved cultural differences were accounted for. There are two possible explanations for this. First, unobserved cultural differences may indeed have some effect on the estimations. Second, the set of analyses that accounted for unobserved cultural differences could be unstable due to a smaller number of participants completing the English version (172 ethnic Chinese or 114 ethnic Malay versus 428 all ethnicities). Both analyses fell short of the required sample size of 175 . Robust conclusions regarding definite equivalence can thus only be drawn for two domains in the English and Chinese language versions, namely physical and environmental and for all domains in the English and Malay versions except environmental. To better understand if there are genuine differences in how the various ethnicities interpreted the items, further qualitative research or cognitive interviews will be useful.

Table 2 WHOQOL-BREF scales: mean (SD) by language version, equivalence margin and adjusted difference between the two language versions

\begin{tabular}{llllllll}
\hline Scale & $\begin{array}{l}\text { English }(n=428) \\
\text { Mean (SD) }\end{array}$ & $\begin{array}{l}\text { Chinese }(n=427) \\
\text { Mean (SD) }\end{array}$ & $\begin{array}{l}\text { Malay }(n=348) \\
\text { Mean (SD) }\end{array}$ & $\begin{array}{l}\text { Equivalence } \\
\text { Margin }^{\mathrm{a}}\end{array}$ & $\begin{array}{l}\text { English vs Chinese } \\
\text { Difference }^{\mathrm{b}}(90 \% \mathrm{Cl})\end{array}$ & $\begin{array}{l}\text { English vs Malay } \\
\text { Difference }^{\mathrm{b}}(90 \% \mathrm{Cl})\end{array}$ & $\begin{array}{l}\text { Chinese vs Malay } \\
\text { Difference }^{\mathrm{b}}(90 \% \mathrm{Cl})\end{array}$ \\
\hline Physical & $74.6(15.8)$ & $71.7(15.7)$ & $72.3(18.9)$ & \pm 5 & $-1.4(-3.1 \text { to } 0.3)^{\dagger}$ & $-0.4(-2.2 \text { to } 1.3)^{\dagger}$ & $-1.0(-2.7 \text { to } 0.8)^{\dagger}$ \\
Psychological & $72.3(14.3)$ & $67.2(16.0)$ & $70.6(14.0)$ & \pm 5 & $-4.1(-5.7 \text { to }-2.5)^{\ddagger}$ & $-0.5\left(-2.2\right.$ to $_{1.3)^{\dagger}}$ & $-3.6(-5.4 \text { to }-1.9)^{\ddagger}$ \\
Social & $73.5(16.2)$ & $68.9(13.4)$ & $74.1(14.8)$ & \pm 5 & $-3.8(-5.5 \text { to }-2.2)^{\ddagger}$ & $1.4(-0.4 \text { to } 3.2)^{\dagger}$ & $-5.2(-7.0 \text { to }-3.5)^{\ddagger}$ \\
Environmental & $71.8(14.3)$ & $68.2(14.6)$ & $68.7(12.8)$ & \pm 5 & $-2.7(-4.2 \text { to }-1.1)^{\dagger}$ & $-1.2(-2.9 \text { to } 0.4)^{\dagger}$ & $-1.4(-3.1 \text { to } 0.2)^{\dagger}$ \\
\hline
\end{tabular}

approximately $0.3 \mathrm{SD}$

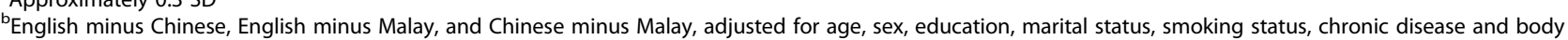
mass index

†Equivalence confirmed; $\neq$ Equivalence inconclusive 
Table 3 WHOQOL-BREF scales: mean (SD) by language version, equivalence margin and adjusted difference between the two language versions for only ethnic Chinese and ethnic Malay participants

\begin{tabular}{|c|c|c|c|}
\hline & & Ethnic Chinese ${ }^{c}$ & Ethnic Malay $^{d}$ \\
\hline Scale & $\begin{array}{l}\text { Equivalence } \\
\text { Margin }^{a}\end{array}$ & English vs Chinese Difference ${ }^{\mathrm{b}}(90 \% \mathrm{Cl})$ & English vs Malay Difference ${ }^{b}(90 \%$ Cl) \\
\hline Physical & \pm 5 & $-0.73(-2.94 \text { to } 1.48)^{\dagger}$ & $-0.39(-3.12 \text { to } 2.33)^{\dagger}$ \\
\hline Psychological & \pm 5 & $-2.37(-4.73 \text { to }-0.02)^{\dagger}$ & $-2.59(-4.98 \text { to }-0.20)^{\dagger}$ \\
\hline Social & \pm 5 & $-1.76(-3.86 \text { to } 0.35)^{\dagger}$ & $-1.99(-4.58 \text { to } 0.59)^{\dagger}$ \\
\hline Environmental & \pm 5 & $-1.32(-3.53 \text { to } 0.89)^{\dagger}$ & $-2.90(-5.17$ to -0.63$) \neq$ \\
\hline
\end{tabular}

${ }^{\text {aApproximately } 0.3 \mathrm{SD}}$

bEnglish minus Chinese, English minus Malay, adjusted for age, sex, education, marital status, smoking status, chronic disease and BMI

${ }^{c}$ Data from 172 ethnic Chinese participants completed the English version questionnaire and 427 ethnic Chinese participants completed the Chinese version questionnaire

${ }^{\mathrm{d} D a t a}$ from 114 ethnic Malay participants completed the English version questionnaire and 345 ethnic Malay participants completed the Malay version questionnaire

${ }^{\dagger}$ Equivalence confirmed; ${ }^{\ddagger}$ Equivalence inconclusive

A strength of this study is that we simultaneously examined three language versions, and these are the three major languages spoken in Singapore. By administering the three language versions using the same set of procedures, the design removed potential confounders and non-comparability between different studies that used different language versions. There are many factors that may affect comparability of study findings. For example, if the studies were conducted at different time periods, sporadic events such as haze due to slash-and-burn farming season in the neighbouring countries, may influence how individuals perceive their HRQoL. In addition, patient experience at the clinics may also influence their HRQoL. Hence, studies conducted in different clinic settings may yield different results. Therefore, by administering the three language versions within the same study using the same set of procedures and in the same settings may help to reduce some of these potential confounders and non-comparability. By over-sampling the Malay and Indian population, the design achieved sufficient precision to assess each language version, thus allowing for comparisons among the three versions. Hence, the conclusion on equivalence between language versions is generalizable to the population. Furthermore, we used a relatively stringent criteria for equivalence by using a MID of 0.3 SD [31]. However, there are potential limitations of the study. The WHOQOL-BREF is designed to be self-administered but in this study, the questionnaire was administered through face-to-face interviews. It has been shown that different modes of survey administration might result in different degree of true responses [34]. However, the bias is consistent throughout all the questionnaires and should not affect the analysis done across the various language versions, which is largely comparative. In this analysis, we accounted for potential confounders including age, sex, education, marital status, smoking status, chronic disease and BMI as these were the information available in our studies. Hence, there may be residual confounding such as those associated with level of physical activities and dietary quality.

\section{Conclusion}

Using a MID of 0.3 SD, we found that the English and Chinese language versions were definitely equivalent for two of four domains. The English and Malay language versions of the WHOQOL-BREF were equivalent for all four domains except environmental. Since none of the domains were clearly not equivalent, it is reasonable to assume that the three language versions of the WHOQOL-BREF may be treated as equivalent. The scores from these language versions may thus be pooled together in the analyses and this will greatly increase the statistical power of the analyses.

\section{Abbreviations}

ANOVA: Analysis of Variance; BMI: Body Mass Index; Cl: Confidence Interval; HrQoL: Health-related Quality of Life; MID: Minimally Important Difference; NHCS: National Heart Centre Singapore; NUH: National University Hospital; PRO: Patient reported Outcomes; SD: Standard Deviation; STEMI: acute myocardial infarction; WHOQOL-BREF: World Health Organization Quality of Life Questionnaire

\section{Acknowledgements}

We would like to acknowledge the support of the interviewers and clinic staff at the National Heart Center Singapore and the Division of Endocrinology, National University Hospital during data collection. We would also like to acknowledge the support of research staff who helped to put together the ethics approval application forms.

\section{Funding}

This study was supported by the Ministry of Health under Health Services Research Competitive Research Grant (HSRG-0045-2013). The study sponsor does not have a role in the study design, the collection, analysis, and interpretation of data, the writing of the article and the decision to submit it for publication.

\section{Availability of data and materials}

The datasets during and/or analysed during the current study are available from the corresponding author on reasonable request. 


\section{Authors' contributions}

All authors contributed to the acquisition, analysis, or interpretation of data, critically revised the manuscript for important intellectual content, gave final approval and agreed to be accountable for all aspects of the work in ensuring that questions relating to the accuracy or integrity of any part of the work are appropriately investigated and resolved. The first draft was prepared by Cheung YB.

\section{Ethics approval and consent to participate}

Ethics approval for this study was obtained from the National Healthcare Group Domain Specific Review Board (Ref. 2013/00747) as well as the SingHealth Centralised Institutional Review Board (Ref. 2015/2041). All participants read and signed the written informed consent form prior to commencement of the interviews.

\section{Consent for publication}

Not Applicable.

\section{Competing interests}

We declare that we have no competing interests.

\section{Publisher's Note}

Springer Nature remains neutral with regard to jurisdictional claims in published maps and institutional affiliations.

\section{Author details}

${ }^{1}$ Centre for Quantitative Medicine, Duke-NUS Medical School, Singapore, Singapore. ${ }^{2}$ Tampere Center for Child Health Research, University of Tampere and Tampere University Hospital, Tampere, Finland. ${ }^{3}$ National Heart Centre Singapore, Singapore, Singapore. ${ }^{4}$ Duke-NUS Medical School, Singapore, Singapore. ${ }^{5}$ Department of Medicine, Yong Loo Lin School of Medicine, National University of Singapore, Singapore, Singapore. ${ }^{6}$ Division of Endocrinology, University Medicine Cluster, National University Hospital, Singapore, Singapore. 'Department of Pharmacy, Faculty of Science, National University of Singapore, Singapore, Singapore. ${ }^{8}$ Saw Swee Hock School of Public Health, National University of Singapore, Singapore, Singapore.

\section{Received: 31 May 2018 Accepted: 28 March 2019}

\section{Published online: 17 April 2019}

\section{References}

1. Basch EM, Abernethy A, Mullins CD, Tiglao MR, Tunis SR. Development of a guidance for including patient-reported outcomes (PROS) in post-approval clinical trials of oncology drugs for comparative effectiveness research (CER). Value heal, vol. 14: Elsevier; 2011. p. A10

2. Kyte D, Ives J, Draper H, Calvert M. Current practices in patient-reported outcome (PRO) data collection in clinical trials: a cross-sectional survey of UK trial staff and management. BMJ Open. 2016;6:e012281.

3. Patrick DL, Guyatt GH, Acquadro C. Patient-Reported Outcomes. Cochrane Handb Syst Rev Interv. Chichester, UK: John Wiley \& Sons, Ltd; p. 531-45.

4. WHO. WHO | WHOQOL: measuring quality of life. WHO. World Health Organization; 2014

5. Quinn DM, Weisz BM, Lawner EK. Impact of active concealment of stigmatized identities on physical and psychological quality of life. Soc Sci Med. 2017:14-7.

6. Hendred SK, Foster ER. Use of the World Health Organization quality of life assessment short version in mild to moderate Parkinson disease. Arch Phys Med Rehabil NIH Public Access. 2016:97:2123-2129.e1.

7. Ross R, Shahrour G, Stidham AW, Delahanty D. The psychometric properties of the World Health Organization quality of life BREF among Thai women who have experienced intimate partner violence. J Nurs Meas. 2017:25:389-99.

8. Kanchanatawan B, Kasalak R. Quality of life in Thai intractable epileptic patients with and without surgery. J Med Assoc Thail. 2012;95:1232-8.

9. Bafna VS, Bafna TA, Sampagar A, Rupavataram SR. 'Quality of life' of parents of children suffering from pediatric malignancies in a low income setting. Indian J Pediatr. 2018.

10. Gangane N, Khairkar P, Hurtig A-K, San Sebastián M. Quality of life determinants in breast Cancer patients in central rural India. Asian Pac J Cancer Prev. 2017;18:3325-32.
11. Ping W, Cao W, Tan H, Guo C, Dou Z, Yang J. Health protective behavior scale: development and psychometric evaluation. Puebla I, editor. PLoS One Public Library of Science. 2018;13:e0190390.

12. Wang $\mathrm{S}$, Lin $\mathrm{P}$, Wang J, Huang M, Lin H, Hsieh C, et al. Mental health status after living donor hepatectomy. Medicine (Baltimore) Medicine. 2017;96: e6910.

13. Osei-Yeboah J, Owiredu WKBA, Norgbe GK, Lokpo SY, Obirikorang C, Alote

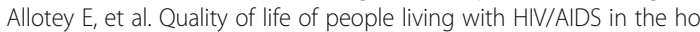
municipality, Ghana: a cross-sectional study. AIDS Res Treat. 2017:1-7.

14. Opoku-Boateng YN, Kretchy IA, Aryeetey GC, Dwomoh D, Decker S, Agyemang SA, et al. Economic cost and quality of life of family caregivers of schizophrenic patients attending psychiatric hospitals in Ghana. BMC Health Serv Res. 2017;17:697.

15. Wham CA, McLean C, Teh R, Moyes S, Peri K, Kerse N. The BRIGHT trial: what are the factors associated with nutrition risk? J Nutr Health Aging. 2014;18: $692-7$.

16. Snell DL, Siegert RJ, Surgenor LJ, Dunn JA, Hooper GJ. Evaluating quality of life outcomes following joint replacement: psychometric evaluation of a short form of the WHOQOL-Bref. Qual Life Res. 2016;25:51-61.

17. Theuns $P$, Hofmans J, Mazaheri M, Van Acker F, Bernheim JL. Cross-national comparability of the WHOQOL-BREF: a measurement invariance approach. Qual Life Res. 2010.

18. Saxena S, Quinn K, Sharan P, Naresh B, Yuantao H, Power M. Cross-linguistic equivalence of WHOQOL-100: a study from North India. Qual Life Res. 2005.

19. Tan MLS, Wee HL, Lee J, Ma S, Heng D, Tai ES, et al. The short form 36 English and Chinese versions were equivalent in a multiethnic Asian population. J Clin Epidemiol Elsevier Inc. 2013;66:759-67.

20. Wee L. Linguistic instrumentalism in Singapore. J Multiling Multicult Dev. 2003:24:211-24

21. Kirkpatrick A. English in ASEAN: implications for regional multilingualism. J Multiling Multicult Dev. 2012

22. Liu J, Tao H. Chinese under globalization: emerging trends in language use in China. World Sci. 2012.

23. Jeon M. Globalization of language and culture in Asia the impact of globalization processes on language. Glob. South Korea's EPIK (English Progr. Korea). 2010.

24. Dixon LQ. The bilingual education policy in Singapore : implications for second language acquisition. 4th Int Symp Biling ed James Cohen, Kara McAlister, Kellie Rolstad Jeff MacSwan. 2005;625-635.

25. Machin D, Cheung YB, Parmar MK. Survival Analysis: A Practical Approach: Second Edition. Surviv. Anal. A Pract. Approach Second Ed. 2006.

26. Rothman KJ. No adjustments are needed for multiple comparisons. Epidemiology [Internet]. 1990 [cited 2019 Jan 23];1:43-6. Available from: http://www.ncbi.nlm.nih.gov/pubmed/2081237.

27. Rothman KJ. Six persistent research misconceptions. J Gen Intern Med. 2014.

28. Cheung Y-B, Thumboo J, Goh C, Khoo K-S, Che W, Wee J. The equivalence and difference between the English and Chinese versions of two major, cancer-specific, health-related quality-of-life questionnaires. Cancer. 2004; 101:2874-80.

29. Wee H-L, Cheung Y-B, Fong K-Y, Luo N, Machin D, Thumboo J. Are Englishand Chinese-language versions of the SF-6D equivalent? A comparison from a population-based study. Clin Ther. 2004;26:1137-48.

30. Norman GR, Sloan JA, Wyrwich KW. The truly remarkable universality of half a standard deviation: confirmation through another look. Expert Rev Pharmacoecon Outcomes Res. 2004:4:581-5.

31. Farivar SS, Liu H, Hays RD. Half standard deviation estimate of the minimally important difference in HRQOL scores? Expert Rev Pharmacoecon Outcomes Res. 2004;4:515-23.

32. Cheung YB, Yeo KK, Chong KJ, Khoo EY, Wee HL. Reliability and validity of the English-, Chinese- and Malay-language versions of the World Health Organization quality of life (WHOQOL-BREF) questionnaire in Singapore. Ann Acad Med Singap. 2017:46:461-9.

33. Wee HL, Yeo KK, Chong KJ, Khoo EYH, Cheung YB. Mean rank, Equipercentile, and regression mapping of World Health Organization quality of life brief (WHOQOL-BREF) to EuroQoL 5 dimensions 5 levels (EQ5D-5L) utilities. Med Decis Mak. 2018;38.

34. Cheung YB, Goh C, Thumboo J, Khoo K-S, Wee J. Quality of life scores differed according to mode of administration in a review of three major oncology questionnaires. J Clin Epidemiol. 2006;59:185-91. 